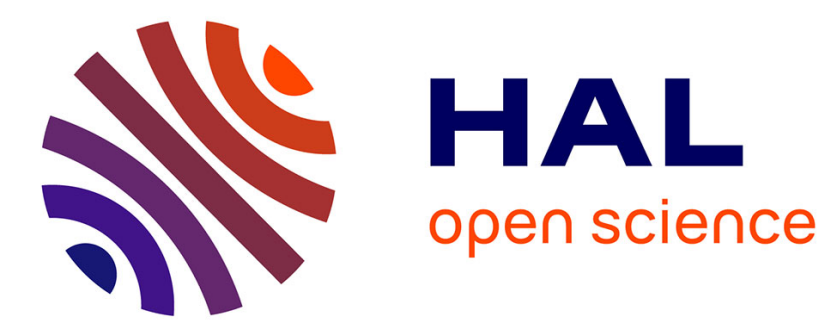

\title{
Pairing effects on electrical properties of n-type CdTe
}

M. Caillot

\section{To cite this version:}

M. Caillot. Pairing effects on electrical properties of n-type CdTe. Revue de Physique Appliquée, 1977, 12 (2), pp.241-244. 10.1051/rphysap:01977001202024100 . jpa-00244151

\section{HAL Id: jpa-00244151 https://hal.science/jpa-00244151}

Submitted on 1 Jan 1977

HAL is a multi-disciplinary open access archive for the deposit and dissemination of scientific research documents, whether they are published or not. The documents may come from teaching and research institutions in France or abroad, or from public or private research centers.
L'archive ouverte pluridisciplinaire HAL, est destinée au dépôt et à la diffusion de documents scientifiques de niveau recherche, publiés ou non, émanant des établissements d'enseignement et de recherche français ou étrangers, des laboratoires publics ou privés. 


\title{
PAIRING EFFECTS ON ELECTRICAL PROPERTIES OF n-TYPE CdTe
}

\author{
M. CAILLOT \\ Groupe de Physique des Solides de l'ENS (*), \\ Université Paris 7, 2, place Jussieu, 75221 Paris Cedex 05, France
}

\begin{abstract}
Résumé. - L'effet Hall et les mesures de la résistivité entre 10 et $300 \mathrm{~K}$ sur des échantillons de CdTe de type $n$, purifié par fusion de zone verticale montrent que l'énergie d'activation des donneurs est anormalement basse et que la mobilité à basse température est plus grande que la mobilité calculée. Ces deux faits expérimentaux sont reliés à l'existence de paires donneur-accepteur distantes. Si de telles paires sont présentes dans le cristal, il doit y avoir aussi des paires proches. Le rapport entre la concentration de donneurs appariés et la concentration totale de donneurs est déduit de nos résultats expérimentaux. Ce rapport dépendant de la configuration des paires proches, un modèle peut être construit dans lequel l'un des éléments de la paire est en site substitutionnel, l'autre étant en site interstitiel. La température de formation des paires serait environ $450 \mathrm{~K}$.
\end{abstract}

Abstract. - Hall effect and resistivity measurements between 10 and $300 \mathrm{~K}$ on n-type CdTe purified by vertical zone melting lead to a donor-to-band activation energy abnormally low and to a mobility at low temperature higher than the calculated values. These two facts are related to the existence of distant donor-acceptor pairs. But if distant pairs are present in the crystal, true close pairs must be also present. The ratio between the concentration of paired donors and the total concentration of donors is deduced from our experimental results. As the ratio depends on the configuration of close pairs, a model can be proposed in which an ion occupies a substitutional site, the other ion occupying the nearest interstitial site. The temperature at which the pairs are formed is about $450 \mathrm{~K}$.

1. Introduction. - Recently, Woodbury [1] studied systematically, by electrical measurements, samples of n-type CdS and n-type CdTe. Among all studied samples, he found two unexpected effects on some samples. Firstly, the donor-to-band activation energy was lower that the usually accepted value

$$
E_{\mathrm{D}}=13.7 \mathrm{meV}[2]
$$

even if he took into consideration the variation of the activation energy with the impurity concentrations. Secondly, the Hall mobility measured at low temperature was much higher than the calculated mobility. Woodbury thought that these two effects were correlated and that they were due to the presence of distant pair of ionized acceptors and donors. But, he did not perform any quantitative study to justify this hypothesis.

In this paper, we present results similar to Woodbury's results for samples of n-type CdTe refined by vertical zone melting. In addition, we show that the experimental results can give information on the microscopic configuration of native defects in CdTe.

2. Experimental results. - We studied the Hall effect and the resistivity of the samples of n-type CdTe grown in the C. N. R. S. Laboratories (Bellevue) and refined by vertical zone melting (these will be denoted VZ samples). In addition, for comparison, we looked also at the electrical properties of another sample refined by the THM technique. The measurements were made between 10 and $300 \mathrm{~K}$. Figure 1 shows the Hall

(*) Laboratoire associé au C. N. R. S.

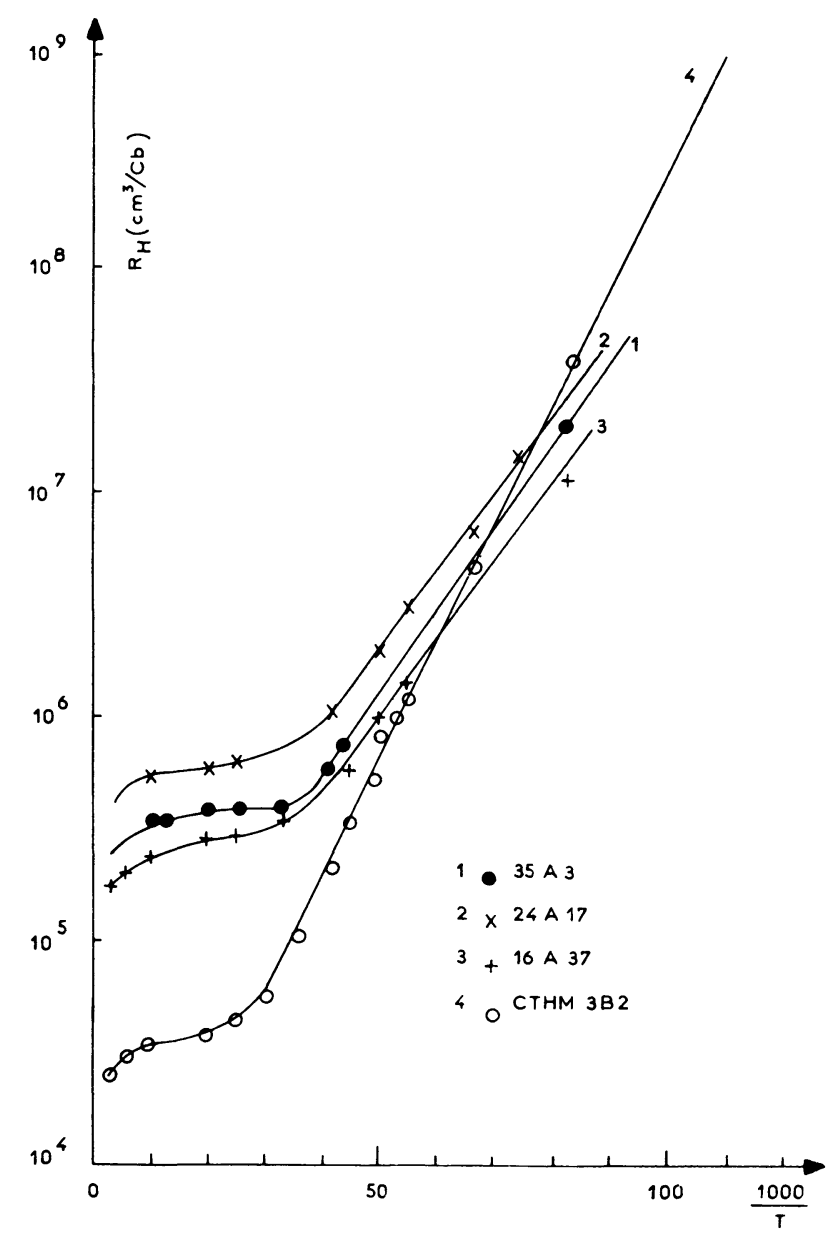

Fig. 1. - Hall constant versus $1 / T$ for three VZ samples and for one THM sample of n-type CdTe. 
constant versus reciprocal temperature and figure 2 the Hall mobility versus temperature. By the usual analysis of Hall curves, we have been able to determine the

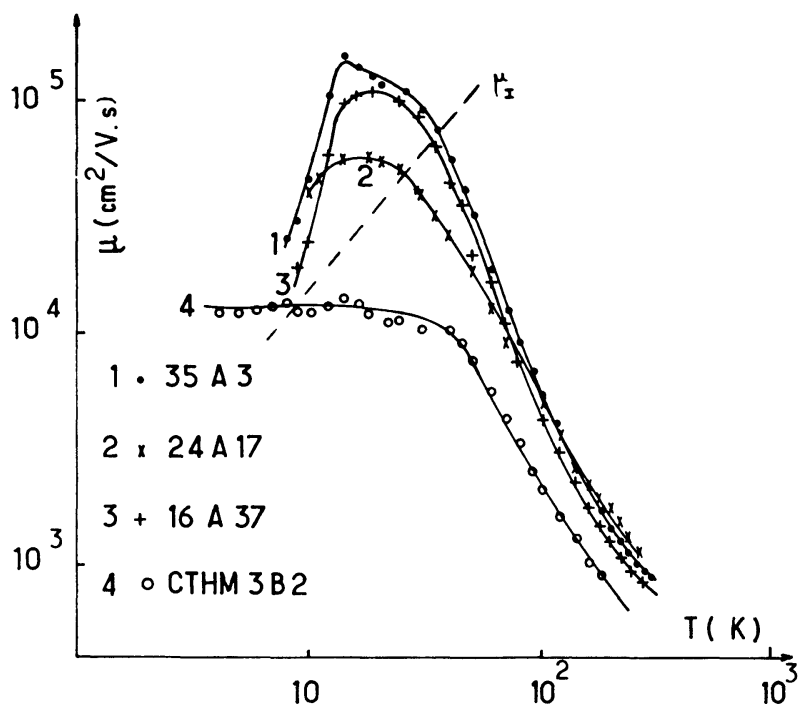

FIG. 2. - Hall mobility versus $T$ for the four same sampler. The straight line $\mu_{\mathrm{I}}$ indicates the contribution of the scattering by ionized impurities to the mobility of the sample $16 \mathrm{~A} 37$.

concentrations of the compensating centres as well as the activation energy of donors to the conduction band. These rsults are shown in table I.

\section{TABLE I}

\begin{tabular}{|c|c|c|c|}
\hline Samples & $\underset{\mathrm{meV}}{E_{\mathrm{D}}}$ & $\mathrm{cm}_{-3}^{N_{D_{3}}}$ & $\underset{\mathrm{cm}^{-3}}{N_{\mathrm{A}}}$ \\
\hline 17 & 7.1 & $\times 10^{14}$ & $2.9 \times 10^{13}$ \\
\hline $35 \mathrm{~A} 3$ & 7.0 & $2.17 \times 10^{14}$ & $\times 10^{13}$ \\
\hline 16 A 27 & 7.0 & $2.07 \times 10^{14}$ & $1.9 \times 10^{13}$ \\
\hline THM 3 B 2 & 10.8 & $2.7 \times 10^{14}$ & $\times 10^{13}$ \\
\hline
\end{tabular}

Inspection of this table shows that the activation energy of donors in the $\mathrm{VZ}$ samples is lower than in the THM sample. In addition, it is lower than the expected value even if the effect of impurity concentration is taken into account. It is well known [3] that in a compensated n-type semiconductor, the activation energy can be written in first approximation as

$$
E_{\mathrm{D}}=E_{\mathrm{Do}}-\alpha N_{\mathrm{A}}^{1 / 3}
$$

where $E_{\mathrm{Do}}$ is the activation energy of donors at zero concentration of acceptors. In CdTe,

$$
E_{\mathrm{DO}}=13.7 \mathrm{meV}
$$

and Woodbury and Aven [4] showed that

$$
\alpha=(3.8 \pm 0.4) \times 10^{-5} \mathrm{meV} . \mathrm{cm}
$$

With the acceptor concentration as determined by Hall effect, we find that $E_{\mathrm{D}}$ should be of the order of $11 \mathrm{meV}$, the value which is found for the THM sample. The activation energy of donors is therefore abnormally low. A similar result was found by Woodbury [1] for about thirty n-type CdS samples and for three samples of CdTe. In addition, he remarked that the samples presenting an abnormally low activation energy had, at low temperature, a mobility higher than the calculated one. Our VZ samples have also a mobility higher than the one calculated on the basis of scattering by the ionized impurities (see Fig. 2). Woodbury suggested that the low activation energy and the high mobility were correlated and could be due to a distant pairing between ionized acceptors and ionized donors. We think that Woodbury's hypothesis is correct. We suggest also, from the work of Reiss et al. [5], that if distant pairing takes place in a semiconductor, i. e. if one ionized donor and one ionized acceptor interact by Coulomb interaction, pairs separated by a very short distance must be also present in the material. The electrical properties are thus modified.

In another paper [6], we show how the electrical properties are modified by pairing in semiconductors, and how the experimental results allow us to determine the respective concentrations of centres which are paired or not. In the following section, we summarize the conclusions of ref. [6].

3. Effect of pairing on the electrical properties of a semiconductor. - Reiss et al. [5] showed that if pairing is present in a semiconductor, some donors will be paired with acceptors in true close pairs by Coulomb interaction and the remaining donors will form with the remaining acceptors what are called distant pairs. The average distance separating a donor from an acceptor in a distant pair is exactly the same whether there is pairing or not. Figure 3 shows the distribution of distances separating a donor from an acceptor in the case where there is pairing and in the case where there is no pairing. The separation of a close pair varies

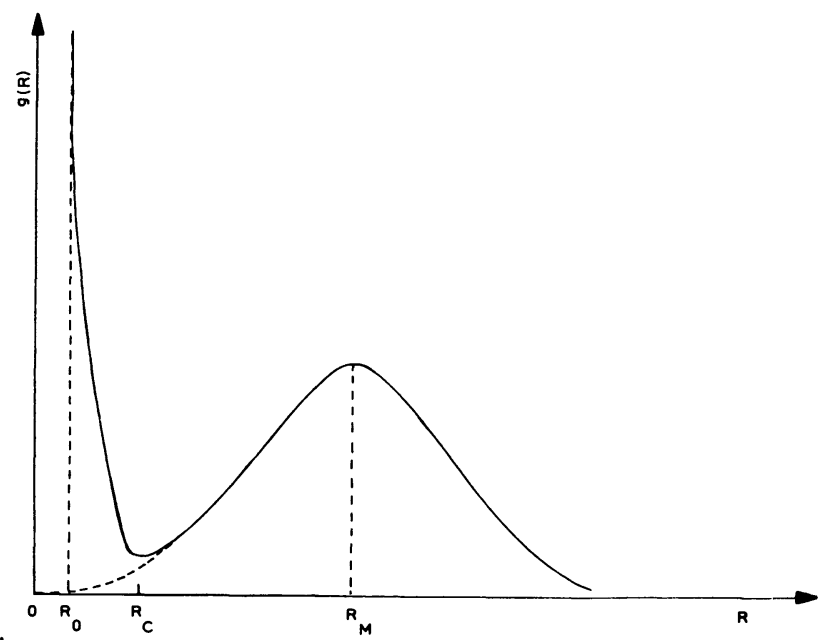

FIG. 3. - Distribution function for ion pairs which interact coulombically versus interionic distance (from Reiss et al. [5]). 
from a minimum distance consistent with the lattice parameters to a distance related to the lowest temperature $T_{\mathrm{D}}$ below which the ions cease to be mobile. This distance is given by

$$
R_{\mathrm{c}}=\frac{1}{2} \frac{q^{2}}{4 \pi \varepsilon_{0} \kappa k T_{\mathrm{D}}} .
$$

Of course, the temperature $T_{\mathrm{D}}$ is characteristic of the growth and/or of the purification process.

In ref. [6], we show that if pairing is present in a semiconductor :

1) The activation energy as determined by the analysis of Hall effect versus $T^{-1}$ is equal to

$$
\varepsilon=E_{\mathrm{DO}}-\frac{q^{2}}{4 \pi \varepsilon_{0} \kappa \bar{R}}
$$

where $\bar{R}$, the average separation of distant pairs, is

$$
\bar{R}=\left[\frac{4}{3} \pi N_{\mathrm{DT}}\right]^{-1 / 3}
$$

From the value of the activation energy, we are therefore able to know the total concentration of paired and unpaired donors.

2) The concentrations of donors and acceptors other than the included ones in close pairs are exactly as determined by the Hall effect.

So, the total concentration of donors in the $\mathrm{VZ}$ samples is about $N_{\mathrm{DT}} \simeq 2.5 \times 10^{16} \mathrm{~cm}^{-3}$ whereas the concentrations of the distant paired donors are given in table I. We see therefore that almost all donors are included in close donor-acceptor pairs and that only a small fraction $(\sim 1 \%)$ are in distant pairs. As the THM sample presents neither an abnormally low activation energy nor a too high mobility, we can conclude that it does not contain any donor-acceptors pairs.

At low temperature, we have seen that the $\mathrm{VZ}$ samples have a mobility higher than the expected one when it is calculated for an electron scattered by single ionized impurities. In fact, the close pairs form dipoles and it is clear that such a dipole will scatter electrons considerably less effectively than the individual ions, so that the mobility will be higher at low temperature. Stratton [7] calculated how the dipole scattering contributes to the mobility. However to perform this calculation, one must know the size of dipoles in addition to their concentration. To calculate this, a model of close pair must be proposed.

4. Model of close pairs. - Reiss et al. [5] showed that in a semiconductor where there is pairing, the ratio between the concentration $N_{\mathrm{DP}}$ of donors paired in close pairs and the total concentration $N_{\mathrm{DT}}$ of donors is given by

$$
\frac{N_{\mathrm{DP}}}{N_{\mathrm{DT}}}=4 \pi h \int_{R_{0}}^{R_{\mathrm{c}}} R^{2} \exp \left[\frac{q^{2}}{4 \pi \varepsilon_{0} \kappa R k T_{\mathrm{D}}}\right] \mathrm{d} R
$$

where $h$ is a normalization constant, $R$ the pair separation, $R_{\mathrm{O}}$ the minimum separation consistent with the lattice parameters, $R_{\mathrm{c}}$ the maximum separation of close pairs and $T_{\mathrm{D}}$ the temperature below which no ions can diffuse to form close pairs.

The normalization constant $h$ depends also on $T_{\mathrm{D}}$, $R_{\mathrm{O}}$, and on the total concentration of donors $N_{\mathrm{DT}}$. Thus we see that the ratio given by equation (4) is a function only of $R_{\mathrm{O}}$ and $T_{\mathrm{D}}$, once $N_{\mathrm{DT}}$ is determined.

The minimum approach distance $R_{\mathrm{O}}$ of both ions is fixed by the cristallographic sites each ion can occupy in the lattice. The lattice parameters are well known [8]. So, the size of a unit cell of CdTe is $a=6.48 \AA$. Each $\mathrm{Cd}(\mathrm{Te})$ has four nearest neighbours of $\mathrm{Te}(\mathrm{Cd})$ at a distance of $2.8 \AA$ and the next-nearest neighbour of atoms of the same kind are at distance of $4.58 \AA$. Two types of donor-acceptor pair can thus exist where each ion occupies a substitutional site :

- The first one is a pair where both ions replace the same kind of atom. In this case, the distance between ions will be $R_{\mathrm{O}}=4.58 \AA$ and the pair will be denoted $S_{\mathrm{A}}-S_{\mathrm{A}}$ with $\mathrm{A}=\mathrm{Cd}$ or $\mathrm{Te}$;

- The second one is a pair in which an ion occupies a group II atom site and the other ion the group VI atom site. The pair separation will be $R_{\mathrm{O}}=2.8 \AA$ and the pair will thus be noted $S_{\mathrm{A}}-S_{\mathrm{B}}$ with $\mathrm{A}=\mathrm{Cd}(\mathrm{Te})$ and $\mathrm{B}=\mathrm{Te}(\mathrm{Cd})$.

In addition, there can be another kind of close pair in which a ion occupies a substitutional site and the other ion an interstitial site. To choose a value for $R_{\mathrm{O}}$, we took arbitrarily the half of the distance Cd-Te which is $R_{\mathrm{O}}=1.4 \AA$. In this case, the pair will be noted $S-I$.

Once $R_{\mathrm{O}}$ was chosen, to get the ratio $N_{\mathrm{DP}} / N_{\mathrm{DT}}$, we calculated separately the normalization constant $h$ for $N_{\mathrm{DT}}=2.5 \times 10^{16} \mathrm{~cm}^{-3}$ and the integral of equation (4). These calculations were made for each values of $R_{\mathrm{O}}$ and for a temperature range of

$$
300 K \leqslant T_{\mathrm{D}} \leqslant 1000 \mathrm{~K} .
$$

The result is shown in figure 4 where the ratio $N_{\mathrm{DP}} / N_{\mathrm{DT}}$ is given as a function of $T_{\mathrm{D}}$ for the different values of $R_{\mathrm{O}}$.

We see that only the pair whose length is $1.4 \AA$ and in which the two ions occupy respectively a substitutional site and an interstitial site lead to a ratio consistent with experiment $\left(N_{\mathrm{DP}} / N_{\mathrm{DT}} \sim 1\right)$. From the variation of $N_{\mathrm{DP}} / N_{\mathrm{D} \text { T }}$ with $T_{\mathrm{D}}$, we obtain the lowest temperature below which the ions cease their migration and their association in close pairs. This temperature is of the order of $450-500 \mathrm{~K}$. This relatively low temperature is not surprising because we know that the VZ samples are unstable when they are heated [9] : a moderate heating above $500 \mathrm{~K}$ is sufficient to change the electrical properties of the material.

As $R_{\mathrm{O}}$ and $T_{\mathrm{D}}$ are now determined, the range of close pair separation extends from $1.4 \AA$ to $18 \AA$. From the experimental value of the mobility at low temperature and from Stratton's calculations [7], we have estimated 


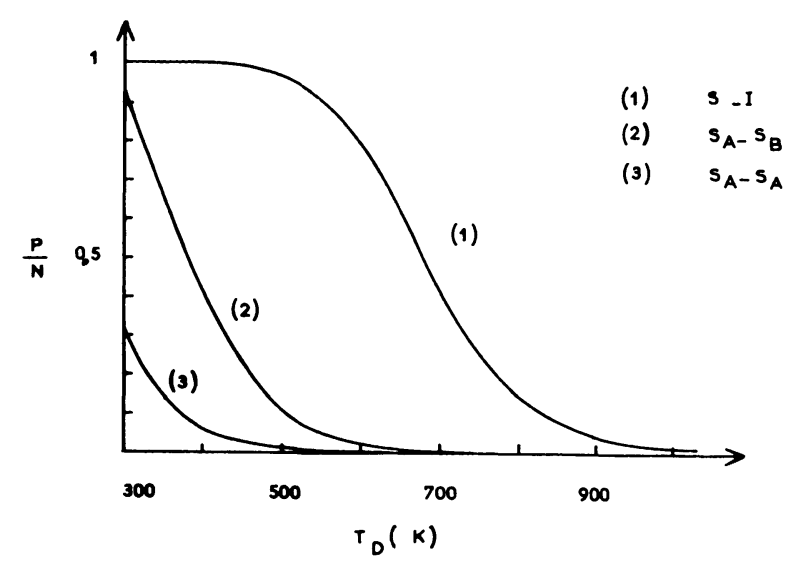

Fig. 4. - Ratio between the fraction of donors paired in close pairs and the total concentration of donors versus the diffusion temperature $T_{\mathrm{D}}$. The ratio is calculated for a total concentration $N_{\mathrm{DT}}=2.5 \times 10^{16} \mathrm{~cm}^{-3}$. The different curves correspond to three possible models of pairs : (1) An ion in interstitial site and the other in substitutional site $\left(R_{O}=1.4 \AA\right)$. (2) Both ions on two different substitutional sites $(\mathrm{A}=\mathrm{Cd}$, $\mathrm{B}=\mathrm{Te})\left(\mathrm{R}_{\mathrm{o}}=2.8 \AA\right)$. (3) Both ions on two equivalent substitutional sites $\left(R_{O}=4.58 \AA\right)$.

the root mean square separation as $\sim 8 \AA$. This value agrees well with the pair separation range especially if we notice that the shortest distant pairs behave as dipolar centres for the electron scattering. Thus the separation range of the dipolar scatterers is greater than the close pair separation range.

Finally, we can speculate on the nature of ions which compose the pair. As the temperature of the pair formation is relatively low, we can assume that only the interstitial ion can move. The question then is which interstitial ? Now, in the II-VI compounds, the elements of the triad $\mathrm{Cu}, \mathrm{Ag}$ and $\mathrm{Au}$ diffuse extremely rapidly as interstitials [10]. But they can also be incorporated in the lattice substituting for the $\mathrm{Cd}$ atom. For example, Woodbury and Aven [11] showed that below $150{ }^{\circ} \mathrm{C}$, the diffusion of $\mathrm{Cu}$ was abnormal and presented a tail characteristic of a system containing simultaneously interstitial and substitutional $\mathrm{Cu}$ atoms. Now, among the elements of the triad $\mathrm{Cu}, \mathrm{Ag}$ and $\mathrm{Au}$, only $\mathrm{Cu}$ is a residual impurity as Triboulet showed it in similar samples to ours [12] and as we saw it in extrinsic photoconductivity where we think that a level could be associated with $\mathrm{Cu}$ [13]. So, the close pairs could be thus formed by two atoms of $\mathrm{Cu}$, one being in interstitial site and the other substituting for a Cd atom. But to justify or to invalidate our assumption, more experimental results must be collected.

5. Conclusion. - In this paper, we have showed that unexpected electrical properties like the activation energy of donors and the mobility measured at low temperature $(T<100 \mathrm{~K})$ can reveal the presence of pairing between ionized donors and acceptors. These pairs could be composed of an ion in an interstitial site and the other ion in a substitutional site separated by $1.4 \AA$. The temperature range where the diffusion of the mobile ion stops is $450-500 \mathrm{~K}$.

Acknowledgements. - We would like to thank Dr. Triboulet for supplying the samples and Dr. Walker for a critical reading of the manuscript.

\section{References}

[1] WoOdbury, H. H., Phys. Rev. B 9 (1974) 5188.

[2] Simmonds, P. E., Stradling, R. A., BirCh, J. R. and Bradley, C. C., Phys. Stat. Sol. (b) 64 (1974) 195.

[3] Debye, P. P. and Conwell, E. M., Phys. Rev. 93 (1954) 963.

[4] Woodbury, H. H. and Aven, M., Phys. Rev. B 9 (1974) 5195.

[5] Reiss, H., Fuller, C. S. and Morin, F. J., Bell Syst. Techn. J. 35 (1956) 535.

[6] CaIllor, M., to be published.

[7] Stratron, R., J. Phys. \& Chem. Solids 23 (1962) 1011.

[8] Rotн, W. L., in Physics and Chemistry of II-VI Compounds, edited by M. Aven and J. S. Prener (North Holland Publishing Company, Amsterdam) 1967.

[9] Triboulet, R., Thesis, Paris (1972), Unpublished.

[10] Woodbury, H. H., in Physics and Chemistry of II-VI Compounds edited by M. Aven and J. S. Prener (North Holland Publishing Company, Amsterdam), 1967.

[11] Woodbury, H. H. and Aven, M., J. Appl. Phys. 39 (1968) 5484.

[12] Triboulet, R., Proc. Intern. Symposium on CdTe (edited by P. Siffert and A. Cornet) Strasbourg, 1971 - Paper V.

[13] Calllot, M., Proc. Intern. Symposium on CdTe (edited by P. Siffert and A. Cornet) Strasbourg 1971, Paper XIII. 